\title{
Shielding Properties Enhancement of Bentonite Clay Nano Particles Coated by Polyvinyl Alcohol Polymer
}

Fawzy Hammad Sallam ( $\sim$ Fozsallam2010@yahoo.com )

Nuclear Materials Authority

Eman Mohamed Ibrahim

Nuclear Materials Authority

Sayed Fahmy Hassan

Nuclear Materials Authority

Ahmed Omar

Military Technical College

\section{Research Article}

Keywords: Calcination process, bentonite Nanoparticles, PVA polymer, Mass attenuation coefficient, WinXCom

Posted Date: July 6th, 2021

DOI: https://doi.org/10.21203/rs.3.rs-645961/v1

License: (c) (i) This work is licensed under a Creative Commons Attribution 4.0 International License. Read Full License 


\title{
Shielding properties enhancement of bentonite clay nano particles coated by polyvinyl alcohol polymer
}

\author{
Fawzy Hammad Sallam¹, Eman Mohamed Ibrahim¹, Sayed Fahmy Hassan² and Ahmed Omar ${ }^{3}$ \\ ${ }^{1}$ Department of Geochemical Exploration, Nuclear Materials Authority, Egypt \\ ${ }^{2}$ Department of Medical and Radiological Research, Nuclear Materials Authority, Egypt \\ ${ }^{3}$ Department of Nuclear Engineering, Military Technical College, Egypt
}

\begin{abstract}
Calcination process is a method used for gamma rays mass attenuation coefficient enhancement of natural bentonite clay nano-particles. This process eliminates water and organic matter from bentonite clay structure which have low mass attenuation coefficient values. There are two opposite effects on mass attenuation coefficient values; oxides content increases after calcination process which enhances mass attenuation coefficient values and particle size of calcinated bentonite increases which decreases mass attenuation coefficient values. In order to enhance mass attenuation coefficient value for natural bentonite, a physical ball milling must introduced after calcination process that decreases particle size. Calcination process is done at $700^{\circ} \mathrm{C}$ for two hours because dehydration is completed above $500{ }^{\circ} \mathrm{C}$ while dehydroxylation observed at $700{ }^{\circ} \mathrm{C}$. Mass attenuation coefficients are measured for calcinated and ball milled bentonite clay at different energies $(662,1173$ and $1332 \mathrm{keV})$ and different pressing pressures (50, 100 and 150 bar). Narrow beam transmission technique and two different sources (Cs-137 and Co-60) are used for mass attenuation coefficient measurements, also particle size are measured by two different methods dynamic light scattering and Williamson-Hall size analyses using XRD patterns. All samples are coated by polyvinyl alcohol polymer.
\end{abstract}

Keywords: Calcination process; bentonite Nanoparticles; PVA polymer; Mass attenuation coefficient; WinXCom

Contact: Fozsallam2010@yahoo.com

\section{Introduction}

The workers in the nuclear materials field are exposed to hazards radiation from artificial and natural sources and this can damage human cell. In order to protect human from radiation, three methods must applied and those are time, distance and shielding [1]. The last parameter is the important one as it doesn't make the human leave work so shielding development are discussed in many studies. The interaction of radiation with matter that gives the fraction of radiation scattered or absorbed are determined by the calculation of attenuation coefficient parameters [2].

Gamma rays and x-rays attenuation for different materials started from very long time ago [3-4], so various attenuation calculations techniques came along in many studies [5]. Different attenuation coefficients that calculated for any shielding material are linear and mass attenuation coefficient. Linear attenuation coefficient is known as the probability of interaction between gamma rays and shielding material per unit path length and represents the main characterizing factor for the penetration and diffusion of gamma rays in a shielding medium ( $\mu$ ) [6]. Gamma rays attenuation depends on many factors like atomic number, photon energy, and density of the shielding material. Mass attenuation coefficient is defined as the linear attenuation coefficient per unit mass of the shielding material [7]. Linear attenuation can be calculated from Lambert's law:

$$
I=I_{o} e^{-\mu X}
$$

Where $\mathrm{I}_{\mathrm{o}}$ intensity of gamma rays without absorber material, $\mathrm{I}$ intensity with the absorber thickness $\mathrm{X}$ and $\mu$ is the linear attenuation coefficient. Mass attenuation coefficient can be determined by knowing the calculated $\mu$ and density of the material $(\rho)$ which equal to $\mu / \rho[8]$. 
Half value layer (HVL) and Tenth value layer (TVL) parameters determine the effectiveness of the shielding material [9].

Due to various application of shielding materials, it required at a particular weight and volume (lighter and more efficient). A new matrix of materials are introduced which consist of a polymer based compound material filled with radiopaque powder. Polymer has a good thermodynamic properties, good radiopaque ability and can easy process in any shape. It can be filled with nano-materials which have been proved that it characterized by high attenuation coefficients than micro one [10-11].

Many researchers have reported enhanced attenuation coefficients of nano-materials at very low energy X-ray and gamma ray having several tens $\mathrm{keV}$ [12-16]. Verdipoor [17] doped silicon resin with $\mathrm{WO}_{3}, \mathrm{PbO}$, and $\mathrm{Bi}_{2} \mathrm{O}_{3} \mathrm{Micro}$ and Nano-particles and calculate shielding parametrs using Monte Carlo (MC) method. He found that shielding samples made of nano-particles had higher mass attenuation coefficients, up to $17 \%$ relative to those made of microparticles. The Performance of nano-particles materials on radiation shielding propertied using Mont Carlo method are illustrated using Iron, bulk lead and lead nano-particles materials to be used as gamma ray shield. It declared that the shielding properties of lead nano-particles are more effective than bulk lead and Iron materials [18].

Addition of nano tungsten oxide to concrete increase mass attenuation coefficient than micro tungsten oxide which simulated and calculated using MCNPX code [19].

Koksal [20] prepared manganese substituted hydroxyapatite nanoparticles by ultrasonic wet chemical method and measure its mass attenuation coefficient at $59.5 \mathrm{keV}$ using germanium detector and the result is compared with a real bone. The results provide information on how gamma rays transmit through real bone. Poly (methyl methacrylate) (PMMA) was reinforced using colemanite $\mathrm{Ca}_{2} \mathrm{~B}_{6} \mathrm{O}_{11} \cdot 5 \mathrm{H}_{2} \mathrm{O}(\mathrm{CMT})$ to increase the radiation shielding capacity of the composite and investigated against gamma rays and neutrons. The experimental results are compared with theoretical one obtained from XCOM and found that the reinforcement increase radiation shielding capacity by 11.1 $\%$ for gamma energy emitted from Cs-137 [21].

Raul Florez [22] added magnetite $\left(\mathrm{Fe}_{3} \mathrm{O}_{4}\right)$ nano-particles to Portland cement and study micro structural, mechanical and gamma attenuation properties of that composite. The addition of magnetite nano-particles improves shielding capability of Portland cement ranging from $2.6 \%$ to $3.1 \%$.

The attenuation coefficients are measured for PVA/ $\mathrm{Pb}\left(\mathrm{NO}_{3}\right)_{2}$ composite using MCNPX5 code and a comparison between experimental and theoretical values obtained from XCOM are done. The results showed that shielding properties of polyvinyl alcohol increased by the increment of lead nitrate [23]. PVA polymer due to its properties such as high optical transmission, water solubility, stable thermal, non-toxic and noncorrosive nature that makes it a good matrix for optoelectronic and supercapacitors [24-25]. In recent days, many glass composites are used for gamma rays attenuation like (20+ $\mathrm{x}) \mathrm{PbO}-10 \mathrm{BaO}-10 \mathrm{Na}_{2} \mathrm{O}-10 \mathrm{MgO}-(50-\mathrm{x}) \mathrm{B}_{2} \mathrm{O}_{3}$ glasses [26], $\mathrm{Sm}^{3+}$ and $\mathrm{Gd}^{3+}$ Co-doped lead phosphate glasses [27] and borate glasses containing heavy metals [28]. Gamma rays shielding of waste soda-lime glass containing various ratios of $\mathrm{Nb}_{2} \mathrm{O}_{5}$ are investigated theoretically using XCOM and MCNP-5 programs in addition to waste soda-lime-silica containing $\mathrm{Bi}_{2} \mathrm{O}_{3}$. The result shows that adding high density oxides to glass improve gamma rays shielding properties $[29,30]$.

The aim of this work is as follows

a- Investigate the structure of calcinated bentonite clay.

b- Shielding parameters enhancement of natural bentonite nanoparticles/ PVA polymer matrix composite by using calcination and ball milled processes.

c- Comparison between experimental and theoretical mass attenuation coefficient values.

\section{Materials and methods}

Natural bentonite samples were brought from El-Mutalla Mountain located in southwestern Sinai, Egypt. Bentonite clay was crushed by hummer to small pieces and then calcinated at $700{ }^{\circ} \mathrm{C}$ in the furnace for two hours where complete dehydration and dehydroxylation are done at that temperature. The calcinated bentonite samples are divided into two parts. The first part calcinated bentonite samples are milled in Fritsch pulverisette, model 02.102 for one hour to have smooth powder. The powder are pressed into cylindrical pellets at different thicknesses and different pressing pressure $(50,100,150$ bar) to produce the first form. The second part of calcinated bentonite samples must have small particle size than the first form so that it is ball milled with high energy Retsch Planetary ball mill PM 400 for three hours to get nano particle size. After ball milled, the calcinated powder were pressed into cylindrical pellets with different thicknesses and different pressing pressure (50,100, 150 bar) so the second form are obtained. The two forms are coated with polyvinyl alcohol (PVA). PVA represents $10 \%$ weight from the all bentonite/PVA matrix weight percentage. The two forms samples are then ready for the measurements (Calcinated 
form and ball mailed form). The density of the samples is calculated by the conventional method for a cylindrical shape as it has a regular shape. The shielding parameters are calculated using narrow beam transmission geometry technique in which a collimator with $22 \mathrm{~mm}$ diameter and $3 \mathrm{~cm}$ height is used. Shielding parameters are calculated at three different energies 662, 1173 and $1332 \mathrm{keV}$ emitted from Cs-137 and Co-60 sources, respectively. The distance between source and samples is $1 \mathrm{~cm}$ and the distance between the collimator and $\mathrm{NaI}$ (Tl) detector is equal to $1 \mathrm{~mm}$. The cylindrical sample and the gamma ray source are stacked in the lead collimator and in the hole inside the collimator also the detector lies in the end of that hole to ensure receiving the narrow beam. A well calibrated gamma ray spectrometer which consists of $3 " \times 3 " \mathrm{NaI}(\mathrm{Tl})$ scintillation detector is used. The detector is protected by $0.6 \mathrm{~cm}$ thickness of copper against induced X-rays and covered by $5 \mathrm{~cm}$ lead while all geometry is protected from environmental radiation by lead bricks. The detector is connected with Tennelec high voltage power supply with HV digital display, Nuclear Enterprises main shaping amplifier, PCA- 8000 computer based, 8192 multichannel analyzer with color graphical display of spectra and high level technical operation features. The measurements of photons with and without shielding material are done for 30 minutes for all sample thicknesses. The all experimental setup of the narrow beam geometry is the same as shown in reference [31] and the shape of the different thicknesses of calcinate bentonite/PVA matrix samples are shown in figure 1.

Fig. 1: Shape of calcinated bentonite/PVA matrix samples with different thicknesses

Gamma transmission factors linear attenuation coefficient, mass attenuation coefficient, half value layer (HVL), tenth value layer (TVL) and mean free path (mfp) are calculated for calcinated and ball milled bentonite/PVA polymer mattresses. Linear attenuation coefficient can be determined using Beer-Lambert equation. It describes the probability of absorption or scattering of incident radiation per unit length.

Mass attenuation coefficient is determined by gamma transmission method and is calculated experimentally using the calculated value of both linear attenuation coefficients and density of the samples. Mass attenuation coefficients can measured theoretically for elements, composites and mixtures of elements. Our samples consider as a mixture of elements and mass attenuation coefficient can determined using the equation:

$$
\mu_{m}=\sum\left(\mu_{m i} \cdot w_{i}\right)
$$

Where $\mu_{m i}$ is the mass attenuation coefficient of the $i$ element and $w_{i}$ is mass percentage of the element $i$ in all mixture [32]. Experimental values of mass attenuation coefficient are set in comparison with theoretical values that calculated from XCOM program and the standard deviation between them are determined from equation 3:

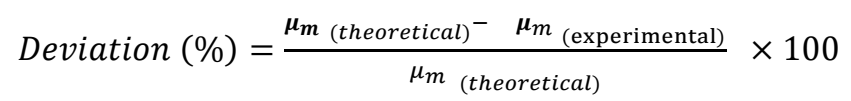

The effective thickness of the shielding material can be calculated by two factors half value layer and tenth value layer. HVL is the thickness of the shielding material that reduces initial intensity of gamma rays to its half value while TVL is the thickness of the shielding material that reduces initial gamma rays intensity to one tenth of its original value and can be calculated using equations 2 and 3 where $\mu$ is linear attenuation coefficient [33].

$$
\begin{aligned}
& H V L=\frac{L n 2}{\mu} \\
& T V L=\frac{\operatorname{Ln} 10}{\mu}
\end{aligned}
$$

The mean free path (mfp) is the average distance between two successive interactions of photons in an absorber material and can be calculated from the equation (5) Where $\mu$ is linear attenuation coefficient [31].

$$
m f p=\frac{1}{\mu}
$$




\section{Results and discussion}

\subsection{Characteristics of calcinated bentonite clay}

Radiation fields become widely used like radiological, diagnostic imaging, radiation therapy, nuclear and industrial applications thus fields can be harmful to human due to hazards radiation. The choice of shielding material has gained more attention to reduce biological effects of radition and depend on type of radiation, energy of that radiation and characteristics of the chosen material [34].

The characteristics of calcinated bentonite clay are illustrated in terms of chemical composition, X-ray patterns, particle size measurements, density measurements and scanning electron microscope. The mineral content of bentonite clay (natural and calcinated) is determined by chemical composition analysis as shown in table 1 . It considers a mixture of elements oxides. The two forms of calcinated bentonite clay have nearly the same chemical composition where the difference between them is the particle size variation due to ball milling process.

Table 1: Chemical composition analysis for natural and calcinated bentonite clay.

Chemical analysis is done in Nuclear Materials Authority laboratories before and after calcination. The remarkable difference in chemical composition between natural bentonite [31] and calcinated bentonite is the values of L.O.I (loss of ignition) and $\mathrm{CaO}$. Organic matter and water content have lower values of gamma rays attenuation so we must eliminate organic matter and water from clay structure by calcination process. Calcination process is done at $700{ }^{\circ} \mathrm{C}$ because dehydration is completed above $500{ }^{\circ} \mathrm{C}$ while dehydroxylation observed at $700{ }^{\circ} \mathrm{C}$. Bentonite samples need to be heated from $100{ }^{\circ} \mathrm{C}$ to $800{ }^{\circ} \mathrm{C}$ because mineralogy and pore structure must not be destroyed by thermal process (complete dehydration and dehydroxylation at $700{ }^{\circ} \mathrm{C}$ ) [35]. Calcinated bentonite consists of number of mineral oxides so it considers a mixture of element oxides that can be used in gamma rays attenuation besides PVA polymer $\left(\mathrm{C}_{2} \mathrm{H}_{4} \mathrm{O}\right)$ in the composite matrix.

Calcinated bentonite is characterized by XRD analysis. XRD patterns of the calcinated bentonite and ball milled calcinated bentonite are illustrated in figure $2(\mathrm{a}$ and $\mathrm{b}$ ). The two patterns contain the same phases and the peaks are located in the same positions. The only differences are the intensity and broadening of the peaks because of the differences in particle size. XRD diffraction pattern revealed two crystalline phases in calcinated and ball milled bentonite clay, Calcite $\left(\mathrm{CaCO}_{3}\right.$, JCPDS card number 00-005-0586) and quartz $\left(\mathrm{SiO}_{2}, \mathrm{JCPDS}\right.$ card number 898935) [36, 37] which represent $(79.6 \%$ and $20.4 \%)$ in calcinated bentonite and $(91 \%$ and $9 \%)$ in ball milled bentonite clay, respectively. The most intense crystalline quartz peak at $2 \theta=26.6^{\circ}(011)$ belongs to hexagonal structure and the most intense crystalline calcite peak at $2 \theta=29.7^{\circ}$. Many methods used XRD diffraction pattern for particle size measurements. In this work XRD diffraction patterns are used by Williamson - Hall size analysis to determine and compare particle size of calcinated and ball milled bentonite clay with the help of X-powder program.

Fig. 2: X-ray diffraction pattern for; (a) calcinated bentonite clay and (b) ball milled calcinated bentonite clay

The perfect crystal extends infinitely in all directions but no crystal is perfect due to their finite size. This deviation leads to a broadening of the diffraction peaks of X-ray patterns. The crystallite size is not generally the same as the particle size due to the formation of polycrystalline aggregates [38].

The particle size of the calcinated bentonite clay is measured by two methods:

a- Dynamic light scattering $\quad$ b- Williamson-Hall size analysis

\section{a- Dynamic light scattering (DLS)}

Dynamic light scattering (DLS) is characterizing the size of the colloidal dispersions of the particles or molecules that undergoing brownian motion using a laser beam for illumination of suspended particles [39]. The fluctuations in the intensity of scattered light are time dependent and analyzed using an autocorrelator. The 
autocorrelator calculate the autocorrelation function of the signal which decays in exponential rate and depend on the diffusion of the particles [40].

As shown in figure 3 (a) which describe the particle size of calcinated bentonite, the lowest particle size is 342 $\mathrm{nm}$ and the highest percentage $92 \%$ of particle size lies between 342 and $615 \mathrm{~nm}$. The calcinated bentonite has a particle size bigger than natural bentonite [31] due to temperature rising which is the fundamental for calcination process. As temperature rises, particle size rises also [39].

In order to decrease the particle size, a physical method is utilized which called ball milling. The calcinated bentonite was ball milled in high energy Retsch Planetary ball mill PM 400 for three hours to decrease the particle size (ball milled calcinated bentonite). To ensure that the particle size is decreased, particle size is measured for ball milled calcinated bentonite and the corresponding result is shown in figure 3 (b).

The figure shows that the lowest size is $105 \mathrm{~nm}$ and the most percentage $65 \%$ lies between 105 and $190 \mathrm{~nm}$ which imply that ball milling is an effective method for decreasing particle size. DLS measurements produce a wide particle size distribution because of agglomeration of nano-particles due to precipitation of bentonite during suspension in the solution.

Fig. 3: DLS analysis for; (a) calcinated bentonite clay and (b) ball milled calcinated bentonite clay

\section{b- Williamson-Hall size analysis}

Another method is needed for measuring particle size of calcinated bentonite and ball milled bentonite for specific determination so Williamson-Hall size analysis is applied which uses XRD patterns and X-powder program software using Gaussian linear fitting method.

$\mathrm{X}$-ray analysis pattern is a powerful tool in the determination of particle size and lattice strain using Williamson-Hall size analysis. The broadening of the peaks are evidence on grain refinement along with lattice strain occurred in the sample. The distribution of the lattice constants in the sample structure due to crystal imperfections like lattice dislocation is called lattice strain [41]. The peaks showed in the x-ray pattern (Figure 2) are sharp intensities and narrow that indicates high quality with good crystallinity and fine grain size. Figure 4 ( $a$ and $b$ ) determine particle size of calcinated bentonite and ball milled calcinatd bentonite by $\mathrm{W}-\mathrm{H}$ size analysis.

The particle size of the calcinated bentonite is $406.27 \mathrm{~nm}$ and the non-uniform lattice strain is 0.518 . The particle size of the calcinated bentonite is higher than that of natural bentonite $(59.79 \mathrm{~nm})$ [31]. Particle size increases with increasing temperature [42].

The calcinated bentonite is high energy ball milled for 3 hours to reduce particle size. Figure 4 declared that the particle size is reduced from $406 \mathrm{~nm}$ to $26.05 \mathrm{~nm}$ and lattice strain increased to 0.619 due to size reduction.

The above figures showed that the two forms are in nanometer scale but ball milled bentonite have the lowest particle size (less than $100 \mathrm{~nm}$ ) so it can increase shielding properties of bentonite clay where nano materials increase relative surface area. This makes nano-particles properties differ than other materials [18].

Fig. 4: Particle size for; (a) calcinated bentonite clay and (b) ball milled calcinated bentonite using W-H size

$$
\text { analysis }
$$

Density is one of the physical constant which is characteristic of the material. It does not vary with the amount or the shape and useful in positively identifying unknown material. Since the samples are solid material and have regular cylindrical shape, it can be calculated from the dimensions (volume) and mass of those samples. The densities of both calcinated and ball milled bentonite samples at different pressing pressure $(50,100$, and 150 bar) are calculated and graphed in figure 5. As shown in the figure, the density increases as pressing pressure increases for calcinated and ball milled bentonite clay. For calcinated bentonite, the density increases from $1.35 \mathrm{~g} / \mathrm{cm}^{3}$ at 50 bar to $1.49 \mathrm{~g} / \mathrm{cm}^{3}$ at 150 bar while for ball milled calcinated bentonite increases from $1.46 \mathrm{~g} / \mathrm{cm}^{3}$ at 50 bar to 1.59 $\mathrm{g} / \mathrm{cm}^{3}$ at 150 bar.

Consequently, the density of the sample increases with decreasing the grain size. At 50 bar, the density of calcinated bentonite is about $1.35 \mathrm{~g} / \mathrm{cm}^{3}$ while ball milled calcinated bentonite pressed at 50 bar is equal to 1.46 $\mathrm{g} / \mathrm{cm}^{3}$ even though they have the same structure (calcinated powder). The residual values of density are the same behavior as 50 bar. The density increases due to two reasons:

(a) Finer grains formation (nanoparticles) results in a decline in pore size [43]. 
(b) More compressibility of the samples produces less volume relative to its mass.

The density measured for natural bentonite is equal to $1.48 \mathrm{~g} / \mathrm{cm}^{3}$ [44]. There are three samples bigger in density than natural bentonite; calcinated bentonite pressed at 150 bar, ball milled calcinated bentonite pressed at 100 bar and ball milled calcinated bentonite pressed at 150 bar. The density increases in the order, natural < calcinated $(150 \mathrm{bar})<$ ball milled (100 bar) < ball milled $(150 \mathrm{bar})$. The highest density measured is for ball milled pressed at 150 bar. The attenuation coefficient increases as density increases [45] so we expect that ball milled bentonite samples have higher mass attenuation coefficient than all studied samples and also higher than natural bentonite.

Fig. 5: Density measurements of calcinated and ball milled bentonite clay at different pressing pressure

The morphological studies of calcinated and ball milled bentonite samples are done by scanning electron microscope. It is a surface analysis technique which used to characterize the composition and morphology of any material. Figure 6 ( $\mathrm{a}$ and $\mathrm{b}$ ) shows scanning electron microscope for calcinated and ball milled bentonite clay.

Calcinated bentonite (Figure 6 (a)) has larger grain size than the other samples. As temperature rises, grain size increases. In case of calcinated bentonite, it has the largest particle size which equal to $406 \mathrm{~nm}$ (Figure 4 (a)). As particle size decreases, more uniform and less particle size distribution observed. Ball milled bentonite clay is the finest grain size as it is more uniform and less particle size distribution (Figure 4 (b)).

Fig. 6: SEM micrograph for; (a) calcinated bentonite clay and (b) ball milled bentonite clay

\subsection{Shielding parameters calculation}

Recently, different materials like clay materials, polymers, ceramics, glasses, alloys and bricks have been investigated as a suitable gamma rays shielding and compared between each other to determine the best shield.

In this work, gamma transmission factors linear attenuation coefficient, mass attenuation coefficient, half value layer (HVL), tenth value layer (TVL) and mean free path $(\mathrm{mfp})$ are calculated for calcinated and ball milled bentonite/PVA polymer mattresses using narrow beam transmission technique in which lead collimator lies above $\mathrm{NaI}(\mathrm{Tl})$ detector is used. These factors are determined at three different energies 662, 1173 and $1332 \mathrm{keV}$ emitted from Cs-137 and Co-60, respectively.

\section{a- Linear attenuation coefficient}

Beer-Lambert equation (1) is used to determine linear attenuation coefficient by plotting $\operatorname{Ln}(\mathrm{Io} / \mathrm{I})$ and thickness (X) where Io intensity of gamma rays without sample thickness and I intensity of gamma rays with sample thickness. The slope of this relation is equal to linear attenuation coefficient. The measured gamma photons with and without two forms of bentonite clay at different pressing pressure and different energies are shown in Table 2 and figure 7 (a, b, c, d, e and f). As in figure 7, (a) calcinated bentonite pressed at 50 bar, (b) calcinated bentonite 100 bar, (c) calcinated 150 bar, (d) ball milled pressed at 50 bar, (e) ball milled 100 bar and (f) ball milled bentonite pressed at 150 bar. It is clear that gamma rays attenuated more through bentonite clay as thickness increase.

The calculated linear attenuation coefficients of the calcinated bentonite $(50,100$, and 150 bar) and ball milled bentonite (50,100 and 150 bar) at different thicknesses and different energies are listed in Table 3.

The relation between linear attenuation coefficient and both density and various gamma rays energy are illustrated in figures 8 ( $a$ and $b$ ) and 9 , respectively.

Both calcinated and ball milled bentonite clay exhibit the same behavior. As density increases, linear attenuation increases for all studied energies and linear attenuation decreases with increasing energy. Ball milled bentonite has linear attenuation higher than calcinated bentonite because it has lower particle size $(26.05 \mathrm{~nm})$ than that for calcinated bentonite $(406.27 \mathrm{~nm}$ ). It is clear linear attenuation increases with decreasing particle size and increasing density.

Linear attenuation coefficient decreases with increasing energy for all investigated bentonite clay. This is due to less gamma ray attenuated through the sample. The transmitted gamma rays increase as energy increase (less interaction between gamma rays and medium). 
Figure 9 shows also that ball milled bentonite clay pressed at 150 bar has the highest linear attenuation coefficient because it has the highest density and lowest particle size. Linear attenuation coefficient values decreases in the order ball milled $(150$ bar $)>$ ball milled $(100$ bar $)>$ ball milled $(50$ bar $)>$ calcinated $(150$ bar $)>$ calcinated $(100$ bar $)>$ calcinated $(50$ bar $)$.

Table 2: Measured gamma photons with and without calcinated bentonite and ball milled bentonite samples [Calcinated, ball milled calcinated (50,100 and 150 bar)] at different thicknesses and different energies.

Fig. 7: Gamma transmission through (a) calcinated bentonite pressed at 50 bar (b) 100 bar, (c) 150 bar, (d) ball milled calcinated bentonite pressed at $50 \mathrm{bar}$, (e) presed at $100 \mathrm{bar}$ and (f) pressed at $150 \mathrm{bar}$ at different thicknesses and different energies

Table 3: Linear attenuation coefficients (cm-1) of all samples at the investigated gamma energies.

Fig. 8: Linear attenuation coefficient versus density for; (a) calcinated bentonite and (b) ball milled calcinated bentonite at different energies

Fig. 9: Linear attenuation coefficient versus energy for calcinated and ball milled bentonite at different pressing pressure

\section{b- Mass attenuation coefficient}

Mass attenuation coefficient is the fundamental shielding parameter that describes the interaction of gamma rays with absorber material. It characterizes the penetration and diffusion of gamma rays in the shielding material. It is considered as a density independent coefficient. Higher mass attenuation means better shielding material [46].

Mass attenuation can be calculated by dividing the calculated linear attenuation on the calculated density of any material. The calculated mass attenuation coefficients of our samples for the two forms of bentonite clay at different energies and different pressing pressure are given in figure 10.

Fig. 10: Mass attenuation coefficient versus energy for calcinated and ball milled bentonite clay at different pressing

$$
\text { pressure }
$$

Figure 10 shows that when energy increases, mass attenuation decreases for all samples types and it illustrates that mass attenuation coefficient of the ball mailed calcinated bentonite pressed at 150 bar has the highest value at any energy because it has the smallest particle size (Figure 4 (a and b)) and density (Figure 5). The mass attenuation decreases in the order ball milled ( $150 \mathrm{bar})>$ ball milled $(100 \mathrm{bar})>$ ball milled $(50 \mathrm{bar})>$ calcinated $(150 \mathrm{bar})>$ calcinated (100 bar)> calcinated (50 bar).

Mass attenuation coefficients $\left(\mathrm{cm}^{2} / \mathrm{g}\right)$ of calcinated bentonite were theoretically calculated using XCOM program. The utilization of XCOM computer code [47], enable us to compare between theoretical mass attenuation coefficient and experimental one. The standard deviation between experimental and theoretical mass attenuation coefficient of calcinated bentonite is tabulated in Table 4.

Table 4: Experimental and theoretical mass attenuation coefficient at different energies for calcinated bentonite clay pressed at 100 bar and the corresponding deviation values (\%). 
The experimental and theoretical mass attenuation coefficients were found to be in a good agreement. The discrepancies are considered not very large because the differences are in the range of the reported experimental errors. The standard deviation is the largest at $662 \mathrm{kev}$ as it equal to $5.4 \%$ while it is the smallest at $1332 \mathrm{kev}$ as it equal to $0.18 \%$. The experimental value of the mass attenuation coefficient of natural bentonite [31] is equal to $0.076 \mathrm{~cm}^{2} / \mathrm{g}$ while the highest mass attenuation coefficient value of ball milled calcinated bentonite pressed at 150 bar is equal to $0.0836 \mathrm{~cm}^{2} / \mathrm{g}$, thus impels that there is a significant enhancement in the mass attenuation coefficient. Not only mass attenuation coefficient of ball milled calcinated bentonite clay pressed at 150 bar has enhanced its value but also ball milled calcinated pressed at $100 \mathrm{bar}$ is equal to $0.08 \mathrm{~cm}^{2} / \mathrm{g}$. It is declared that due to this enhancement in mass attenuation coefficient values, the calcination process is an effective method to develop natural bentonite material as a shield for gamma rays by decreasing the particle size below $100 \mathrm{~nm}$ by an effective ball milling or another method. The mass attenuation coefficient of natural bentonite represents $69 \%$ from lead mass attenuation coefficient $[47,31]$ while the enhanced mass attenuation coefficient of ball milled calcinated bentonite (pressed at 150 bar) represents $75.4 \%$.

The highest mass attenuation coefficient value of the studded samples is ball milled bentonite pressed at 150 bar so we can compare it with other shielding material as in table 5.

Table 5: Comparison between mass attenuation coefficients of ball milled calcinated bentonite pressed at 150 bar and other shielding materials.

\section{c- Half value layer (HVL) and tenth value layer (TVL)}

It is better to express the attenuation of gamma rays in terms of effective shielding thickness for applications purpose.

The less HVL and TVL of the shielding material, the better shielding properties it has. Thus the shielding effectiveness of the calcinated bentonite clay is inversely proportional to its HVL value. The energy dependence of HVL and TVL values for calcinated bentonite and ball milled bentonite clay at different pressing pressure are illustrated in figures 11 and 12.

Fig. 11: Variation of HVL with energy for calcinated and ball milled bentonite clay at different pressing pressure

It is obvious from figure 11 that the gradual increase in HVL with photon energy indicates that thicker shields are needed against high gamma radiation. HVL parameter can be employed to distinguish between samples in terms of their shielding effectiveness. The lowest value of HVL is for the ball milled calcinated bentonite pressed at 150 bar. It is the chosen bentonite sample as it is more effective in protection against gamma rays than other samples. It requires less thickness for gamma rays protection than other samples for all studied energies. The required thickness from bentonite sample is $(5.2 \mathrm{~cm})$ for the protection against $662 \mathrm{keV}$ while the highest thickness value is for the calcinated bentonite pressed at (50 bar) which equal to $8.45 \mathrm{~cm}$. Tenth value layer (TVL) exhibit the same behavior as HVL as shown in figure 12 .

The ball milled calcinated bentonite pressed at 150 bar has the lowest HVL and TVL values. It has tenth value layer $(17.3 \mathrm{~cm})$ for the protection against $662 \mathrm{keV}$ while the highest TVL $(28.08 \mathrm{~cm})$ for the calcinated bentonite pressed at (50 bar) at the same energy. The ball milled calcinated bentonite pressed at 150 bar has the minimum thickness value while it has the higher density and lower particle size than other samples (see figures 5 and 4 (b)).

Fig. 12: Variation of TVL with energy for calcinated and ball milled bentonite clay at different pressing pressure

\section{d- Mean free path}

The variation of mean free path (mfp) values with energy of studied samples are shown in figure 13. Mean free path follows a decreasing order with increasing energy. Low values of mean free path are the indication of the increase of probability of gamma rays to get attenuated. Figure 13 showed that minimum value of the mean free path is observed for ball milled calcinated bentonite sample pressed at 150 bar with the highest density $\left(1.59 \mathrm{~g} / \mathrm{cm}^{3}\right)$. Mfp values increase as gamma ray energy increase for all studied samples where low energy photon can losses its energy in a short distance while high energy one needs a large distance.

The best shielding characteristics (linear attenuation, mass attenuation, HVL, TVL and mean free path) obtained is for ball milled calcinated bentonite pressed at 150 bar. Its shielding properties has enhanced in comparison with natural bentonite because of the influence of calcination process and ball milling. 
Fig. 13: Mean free path versus photon energy for calcinated and ball milled bentonite clay at different pressing pressure

\section{Conclusion}

In order to evaluate mass attenuation coefficient for natural bentonite, calcinations process is introduced to get rid of water and organic matter from the structure. Water has less ability for gamma rays shielding. Mass attenuation coefficient of calcinated bentonite has been calculated and found that it is less than natural bentonite, this is due to particle size increases from $59.79 \mathrm{~nm}$ for natural to $406.27 \mathrm{~nm}$ for calcinated bentonite and lattice strain increased from 0.168 to 0.518 , respectively. The particle size must decreases so a physical ball milled is needed. The particle size decreases from $406.27 \mathrm{~nm}$ to $26.05 \mathrm{~nm}$. Due to that decrease in particle size, mass attenuation increased. Ball milled calcinated bentonite clay has the higher mass attenuation coefficient $\left(0.0836 \mathrm{~g} / \mathrm{cm}^{2}\right.$ at $\left.662 \mathrm{keV}\right)$ than natural and ground bentonite. By comparing the value of mass attenuation coefficient of ball milled calcinated bentonite pressed at 150 bar and lead, it represents $75.5 \%$ from lead value at photon energy $662 \mathrm{keV}$. The value increases from $69 \%$ for natural bentonite and $75.3 \%$ for ground bentonite to $75.5 \%$ for ball milled calcinated bentonite. The result of this raising proves the efficiency of calcination process in shielding properties enhancement but it must accompanied with ball milling process for particle size reduction.

\section{References}

[1] Mavi, B.: Experimental investigation of X-ray attenuation coefficients for granites, Annals of Nuclear Energy, 44, pp 22-25 (2012).

[2] Charanjeet, S.C., Singh, T., Kumar, A., Mudahar G.S.: Energy and chemical composition dependence of mass attenuation coefficients of building materials, Annals of Nuclear Energ, 31, pp 1199-1205 (2004).

[3] Fano, U.: Gamma-ray attenuation, Part 2, Nucleonics, vol 11 (9), pp 55-60 (1953).

[4] White, G.R.: X-ray Attenuation Coefficients from $10 \mathrm{keV}$ to $100 \mathrm{MeV}$, NBS Report, pp 10033-10041 (1952).

[5] Creagh, D.C., Hubbell, J.H.: Problems associated with the measurement of X-ray attenuation coefficients. II. Carbon report on the international union of crystallography X-ray attenuation project, Acta Crystallographica, vol A, 46, pp 402-408 (1990).

[6] Woods, J.: Computational Methods in Reactor Shielding, Pergamon Press, New York (1982).

[7] Kaplan, M.F.: Concrete Radiation Shielding. Longman Scientific and Technology, Longman Group UK Limited, Essex, England (1989).

[8] Akkurt, I., Altindag, R., Gunoglu, K., Sarikaya, H.: Photon attenuation coefficients of concrete including marble aggregates, Annals of Nuclear Energy, vol 43, pp 56-60 (2012).

[9] Tsoulfaniidis, N.: Measurement and detection of radiation. Hemisphere Publishing Corporation, Mcgraw-Hill Book Company, pp. 151-163 (1983).

[10] Yu, D., Shu-Quan, C., Hong-Xu, Z., Chao, R., Bin, K., Ming-Zhu, D. and Yao-Dong, D.: Effects of $\mathrm{WO}_{3}$ Particle Size in $\mathrm{WO}_{3} /$ Epoxy Resin Radiation Shielding Material, CHIN. PHYS. LETT, 29, pp. 10108102 (2012).

[11] Kim, J., Seo, D., Lee, B. C., Seo, Y.S., Miller, W. H.: Nano-W Dispersed Gamma Radiation Shielding Materials, Advanced Engineering Materials, DOI: 10.1002/adem.201400127 (2014).

[12] Nambiar, S., Osei, E. K., Yeow, J. T. W.: Polymer nanocomposite-based shielding against diagnostic X-rays, Journal of Applied Polymer Science, 127(6), pp 4939-4946,. doi:10.1002/app.37980 (2012).

[13] Botelho et al.: X-ray transmission through nanostructured and microstructured $\mathrm{CuO}$ materials, Applied Radiation and Isotopes, 69(2), pp 527-530. doi:10.1016/j.apradiso.2010.11.002 (2011).

[14] Künzel, R., Okuno, E.: Effects of the particle sizes and concentrations on the X-ray absorption by $\mathrm{CuO}$ compounds, Applied Radiation and Isotopes, 70(4), 781-784. doi:10.1016/j.apradiso.2011.12.040 (2012).

[15] Noor Azman, N. Z., Siddiqui, S. A., Low, I. M.: Characterization of micro-sized and nano-sized tungsten oxide-epoxy composites for radiation shielding of diagnostic X-rays. Materials Science and Engineering: C, 33(8), pp 4952-4957. doi:10.1016/j.msec.2013.08.023 (2013).

[16] Uhm, Y. R., Kim, J., Jae Son, K., Sung Kim, C.: Effect of particle size, dispersion, and particle-matrix adhesion on W reinforced polymer composites, Res Chem Intermed, 40, 2145-2153, DOI 10.1007/s11164013-1110-7 (2014). 
[17] Verdipoor, K., Alemi A., Mesbahi, A.: Photon mass attenuation coefficients of a silicon resin loaded with $\mathrm{WO}_{3}$, $\mathrm{PbO}$ and $\mathrm{Bi}_{2} \mathrm{O}_{3}$ Micro and Nano-particles for radiation shielding, Radiation Physics and Chemistry, 147, pp 85-90 (2018).

[18] El- Sawy, A. A.: Performance of Nanoparticle Materials on Radiation Shielding Properties Using Mont Carlo Method, The International Journal of Engineering and Science (IJES), ISSN (e): 2319 - 1813 (2017).

[19] Tekin, H. O., Singh, V. P., Manici, T.: Effects of micro-sized and nano-sized $\mathrm{WO}_{3}$ on mass attenuation coefficients of concrete by using MCNPX code, Applied Radiation and Isotopes, http://dx.doi.org/10.1016/j.apradiso.2016.12.040 (2016).

[20] Koksal, O.K., Apaydın, G., Tozar, A., Karahan, İ.H., Cengiz, E.: Assessment of the Mass Attenuation Parameters with using Gamma- Rays for Manganese Substituted Nano Hydroxyapatite, Radiation Physics and Chemistry, https://doi.org/10.1016/j.radphyschem.2019.02.040

[21] Bel, T., Arslan, C., Baydogan, N.: Radiation Shielding Properties of Poly (Methyl Methacrylate) / Colemanite Composite for the use in Mixed Irradiation Fields of Neutrons and Gamma Rays, , Materials Chemistry and Physics, doi: 10.1016/j.matchemphys.2018.09.014 (2018).

[22] Florez, R., Colorado, H. A., Alajo, A., Giraldo, C. H.C.: The material characterization and gamma attenuation properties of Portland cement- $\mathrm{Fe}_{3} \mathrm{O}_{4}$ composites for potential dry cask applications, Progress in Nuclear Energy, 111, pp 65-73 (2019).

[23] Shams A.M., Issa, A.M.A., Mostafa, T. A., Hanafy, M. D., Xuee, X.: Comparison study of photon attenuation characteristics of Poly vinyl alcohol (PVA) doped with $\mathrm{Pb}\left(\mathrm{NO}_{3}\right)_{2}$ by MCNP5 code, XCOM and experimental results, Progress in Nuclear Energy, 111, pp 15-23 (2019).

[24] Behzadi Pour, G., Fekri Aval, L., Mirzaee, M.: Flexible graphene super capacitor based on the PVA electrolyte and $\mathrm{BaTiO}_{3}$ /PEDOT: PSS composite separator, Journal of Materials Science, Materials in Electronics, 29, pp 17432-17437 (2018).

[25] Fekri Aval, L., Ghoranneviss, M., Behzadi Pour G.: High-performance supercapacitors based on the carbon nanotubes graphene and graphite nanoparticles electrodes, Heliyon, 4 (11), pp e00862. https://doi.org/10.1016/j.heliyon.2018.e00862 (2018).

[26] Kumar et al, Physical, structural, optical and gamma ray shielding behavior of $(20+\mathrm{x}) \mathrm{PbO}-10 \mathrm{BaO}-10$ $\mathrm{Na} 2 \mathrm{O}-10 \mathrm{MgO}-(50-\mathrm{x}) \mathrm{B} 2 \mathrm{O} 3$ glasses, Physica B: Physics of Condensed Matter, doi:10.1016/j.physb.2018.10.001 (2018).

[27] Kaur, P., Singh D., Singh, T.: $\mathrm{Sm}^{3+}$ and $\mathrm{Gd}^{3+}$ Co-doped Lead Phosphate Glasses for $\gamma$-Rays Shielding and Sensing, Journal of Luminescence, https://doi.org/10.1016/j.jlumin.2019.01.019 (2019).

[28] Sayyed, et al, Physical, structural, optical and gamma radiation shielding properties of borate glasses containing heavy metals $\left(\mathrm{Bi}_{2} \mathrm{O}_{3} / \mathrm{MoO}_{3}\right)$, Journal of Non-Crystalline Solids, 507, pp 30-37 (2019).

[29] Kurtulus et al, The effect of $\mathrm{Nb}_{2} \mathrm{O}_{5}$ on waste soda-lime glass in gamma-rays shielding applications, $J$ Mater Sci: Mater Electron, 32, pp 4903-4915 (2021).

[30] Akkurt, I., Malidarre, R.B., Kavas, T., Monte Carlo simulation of radiation shielding properties of the glass system containing $\mathrm{Bi}_{2} \mathrm{O}_{3}$, Eur. Phys. J. Plus, pp 136:264 (2021).

[31] Hager, I. Z., Hassan, S.F., Rammah, Y. S., Othman, H.O., Ibrahim, E.M., Sallam, F.H.: Nano-structured natural bentonite clay coated by polyvinyl alcohol polymer for gamma rays attenuation, Journal of Theoretical and Applied Physics https://doi.org/10.1007/s40094-019-0332-5 (2019).

[32] Degrelle, D., Mavon, C., Groetz, J.E.: Determination of mass attenuation coefficient by numerical absorption calibration with Monte-Carlo simulations at $59.54 \mathrm{keV}$. Nuclear Instruments and Methods in Physics Research Section A: Accelerators, Spectrometers, Detectors and Associated Equipment, Elsevier, , 816, pp.47-52. $<10.1016 /$ j.nima.2016.01.075>. <hal-01315381> (2016).

[33] El-bashir, B.O., Sayyed, M. I, Zaid, M. H. M, Matori, K. A.: Comprehensive study on physical, elastic and shielding properties of ternary $\mathrm{BaO}-\mathrm{Bi}_{2} \mathrm{O}_{3}-\mathrm{P}_{2} \mathrm{O}_{5}$ glasses as a potent radiation shielding material, Journal of Non-crystalline Solids, 468, pp 92 (2017).

[34] Gonzalez et al.: Impact of prone versus supine positioning on small bowel dose with pelvic intensity modulated radiation therapy, Adv. Radiat. Oncol. doi:10.1016/j.adro.2017.01.005 (2017).

[35] Sarikaya, Y., Refona, M., Baran, B., Alemparoglu, T.: The effect of thermal treatment on some of the physicochemical properties of a bentonite, Clays and Clay Minerals, 48, pp 5. 557-562 (2000).

[36] Barhoum et al, A green, simple chemical route for the synthesis of pure nanocalcite crystals. Cryst. Growth Des. https: //doi.org/10.1021/cg501 121t (2014).

[37] Suriyanarayanan, N., Nithin, K. V. K., Bernardo, Mullite, E.: glass ceramics production from coal ash and alumina by high temperature plasma, Journal of Non-Oxide Glasses, 1(4), pp. 247-260 (2009). 
[38] Ramakanth, K.: Basic of Diffraction and Its Application. I.K. International Publishing House Pvt. Ltd, New Dehli, (2007).

[39] Peters, R.: Fiber optic device for detecting the scattered light of fluorescent light from a suspension. US Patent 6,016,195 (2000).

[40] Dahneke, B.E., Measurement of suspended particles by quasi-elastic light scattering. Wiley, New York (1983).

[41] Johan, M. R., Mohd Suan, M. S., Hawari, N. L., Ay Chin, H.: Annealing Effects on the Properties of Copper Oxide Thin Films Prepared by Chemical Deposition, Int. J. Electrochem. Sci., 6, pp 6094 - 6104 (2011).

[42] Ungar, T.: Characterization of nanocrystalline materials by X-ray lineprofile analysis T: J. Mater. Sci, 42, pp.1584 (2007).

[43] Rajabi, A., Ghazali, M.J., Daud, A.R.: Chemical composition, microstructure and sintering temperature modifications on mechanical properties of TiC-based cermet - A review, Materials and Design, 67, pp. 95-106 (2015).

[44] Sallam et al, Evaluation of gamma rays shielding competence for bentonite clay /PVA polymer matrix using MCNPX code, Arab J. Nucl. Sci. Appl., 53, 2, pp.177-188 (2020).

[45] Akkurt et al, Determination of Some Heavyweight Aggregate Half Value Layer Thickness Used for Radiation Shielding, Acta Physica Polonica A, 121 (2012).

[46] Abdel-Rahman M.A.,Badawi E.A., Abdel-Hady Y.L., Kamel N.: Effect of sample thickness on the measured mass attenuation coefficients of some compounds and elements for 59.54, 661.6 and $1332.5 \mathrm{keV}$ c-rays. Nucl Instrum Methods Phys Res, A 447, pp. 432-436 (2000).

[47] Berger et al, XCOM: photon cross section database, http://www. Nist.gov/pml/ data/xcom/index.cfm, U.S.

[48] Biswas, R., Sahadath, H., Mollah, A.S., Huq, M.F.: Calculation of gamma-ray attenuation parameters for locally developed shielding material, polyboron. J. Radiat. Res. Appl. Sci. 9, pp. 26-34 (2016).

[49] Alam et al, Attenuation coefficients of soils and some building materials of Bangladesh in the energy range 276-1332 keV, Technical note. Appl. Radiat. Isot. 54(6), pp. 973-976 (2001).

[50] Mahmoud et al, Fabrication, characterization and gamma rays shielding properties of nano and micro lead oxide-dispersed-high density polyethylene composites. Radiat Phys Chem, 145, pp. 160-173 (2018a).

[51] Abbasova, N., Yüksel, Z., Abbasov, E., Gülbiçim, H., Tufan, M.Ç., investigation of gamma-ray attenuation parameters of some materials used in dental applications. Results Phys, 12, pp. 2202-2205 (2019).

[52] Li, R., Gu, Y., Wang, Y., Yang, Z., Li, M., Zhang, Z., Effect of particle size on gamma radiation shielding property of gadolinium oxide dispersed epoxy resin matrix composite. Mater Res Express, 4(3), pp 035035 (2017).

[53] Nasehi, F., Ismail, M., Evaluation of $\mathrm{X}$ and gamma-rays attenuation parameters for polyacrylamide and $\mathrm{ZnO}$ composites as light shielding materials using MCNP and X-COM simulation. Nucl Med Radiat Ther, 10(404): pp 2 (2019).

[54] Obaid, S.S., Sayyed, M.I., Gaikwad, D.K., Pawar, P.P.: Attenuation coefficients and exposure buildup factor of some rocks for gamma ray shielding applications. Radiat. Phys. Chem, 148, pp 86-94 (2018). 
Figures

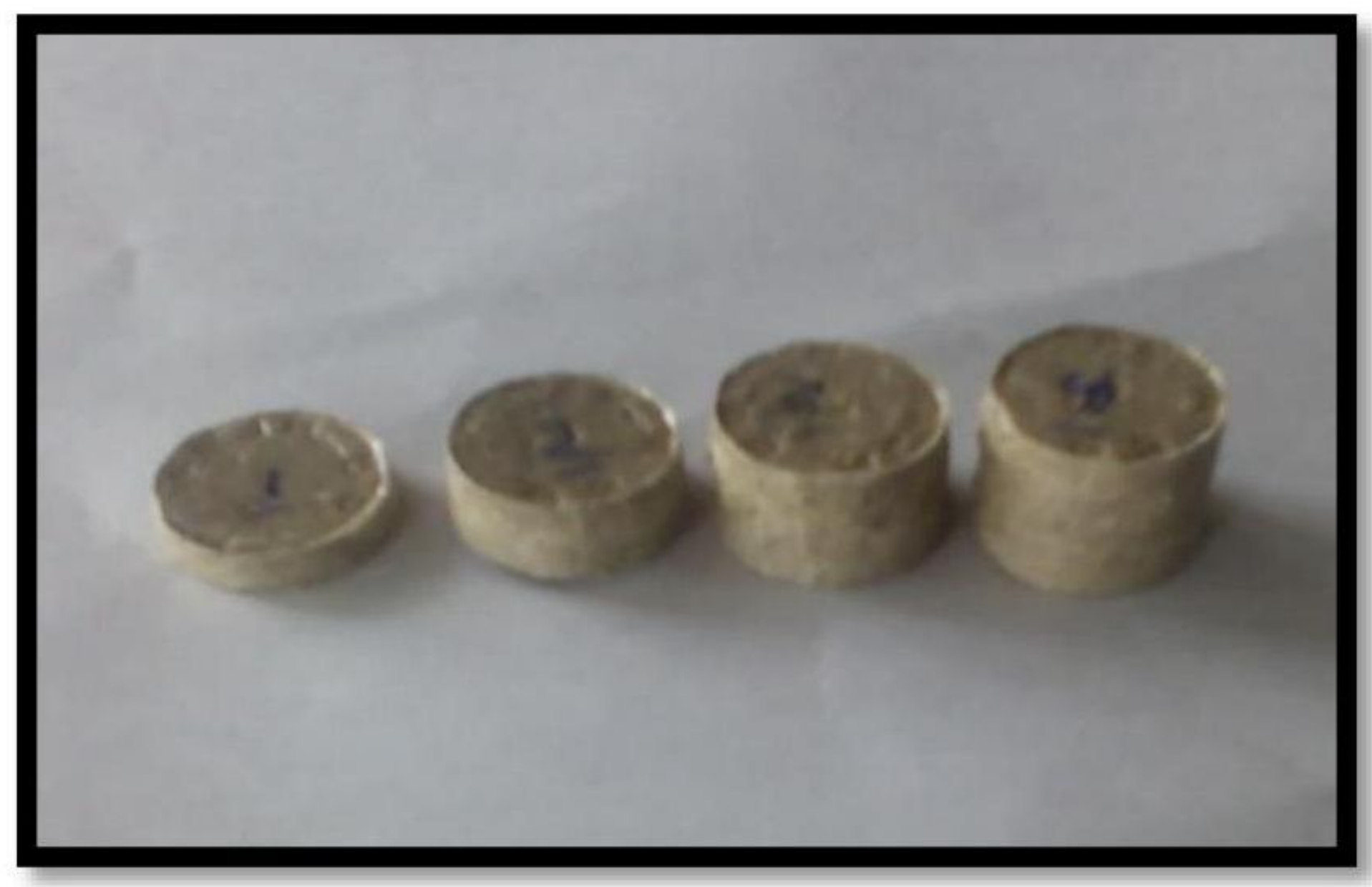

Figure 1

Shape of calcinated bentonite/PVA matrix samples with different thicknesses. 

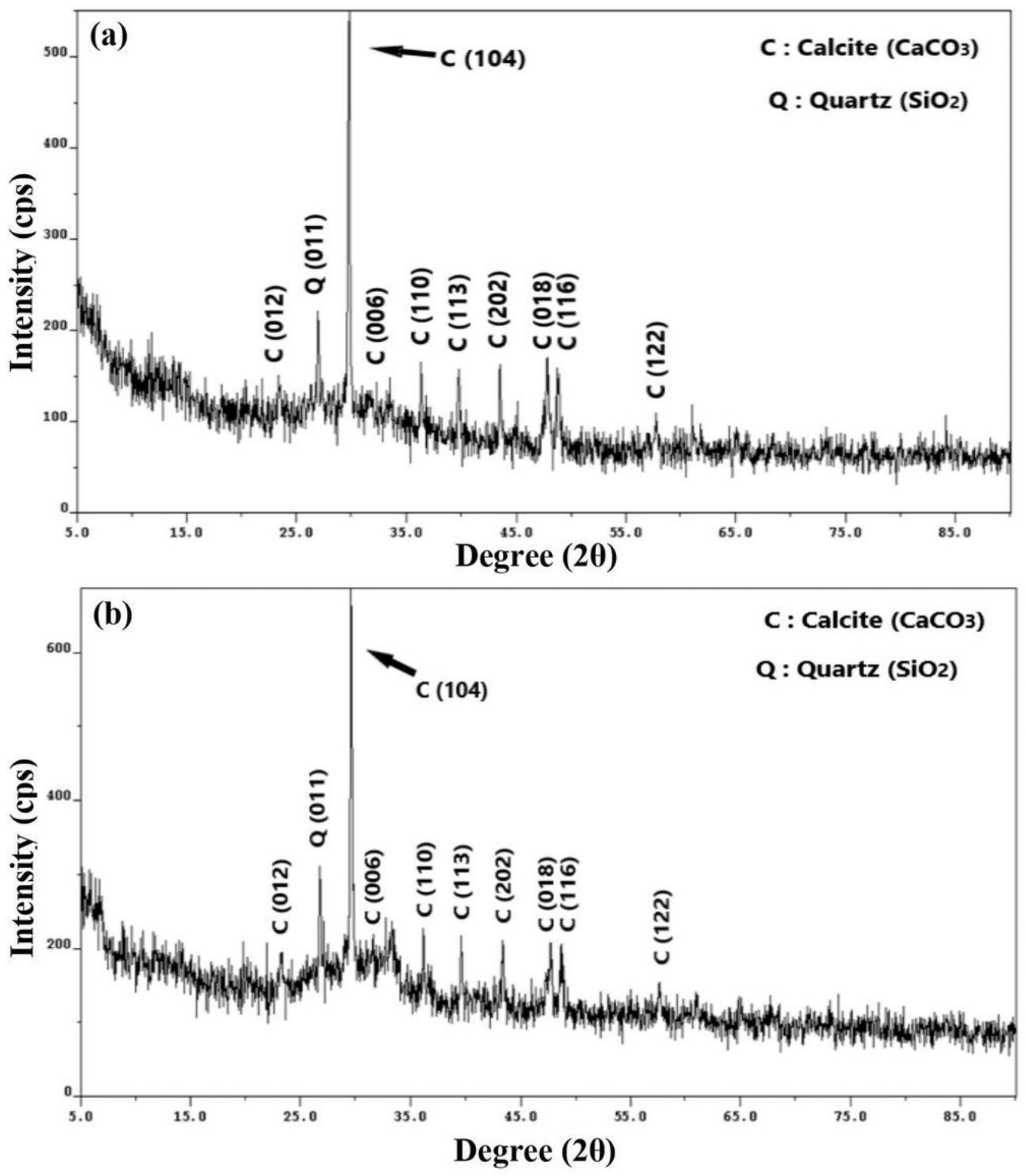

Figure 2

X-ray diffraction pattern for; (a) calcinated bentonite clay and (b) ball milled calcinated bentonite clay. 

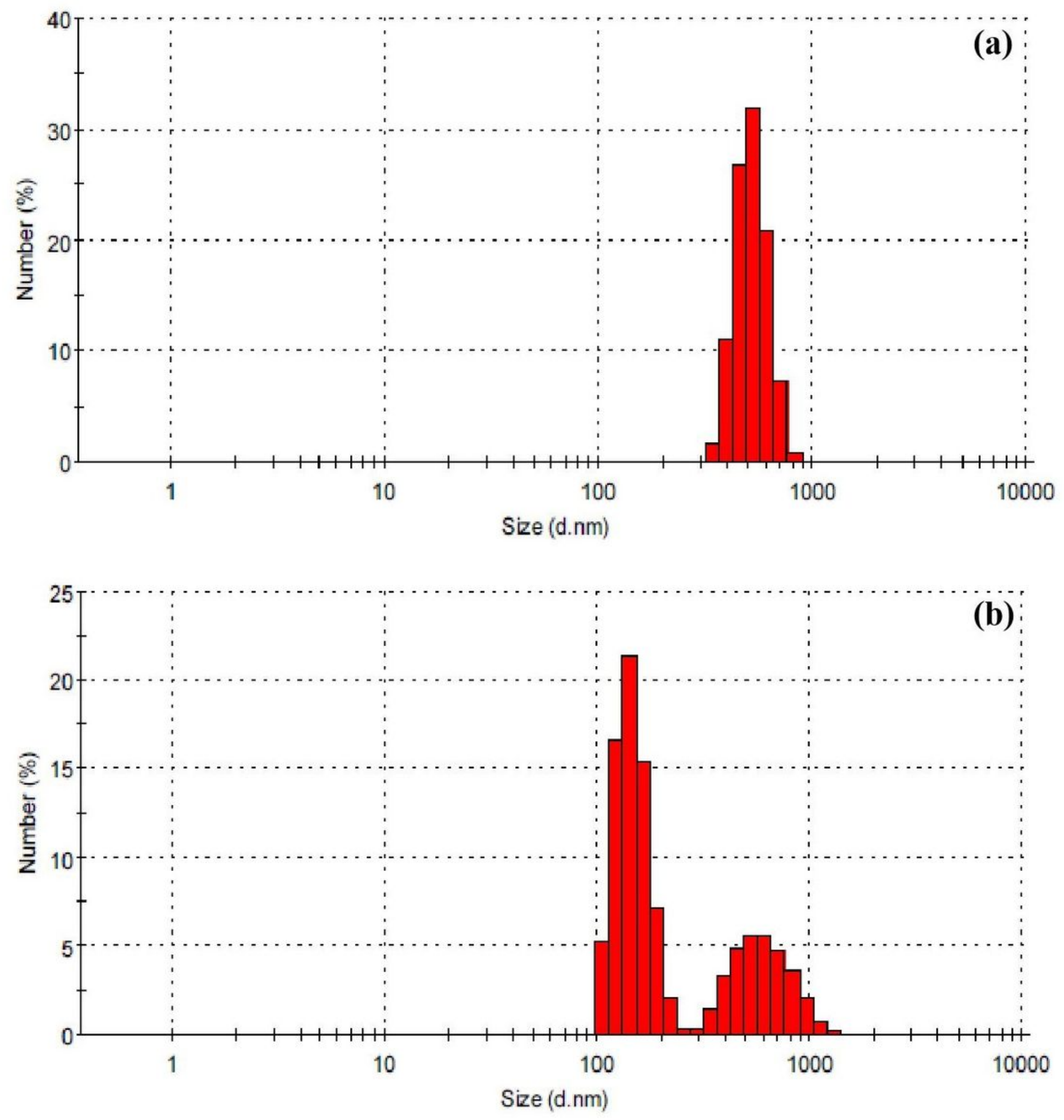

Figure 3

DLS analysis for; (a) calcinated bentonite clay and (b) ball milled calcinated bentonite clay. 

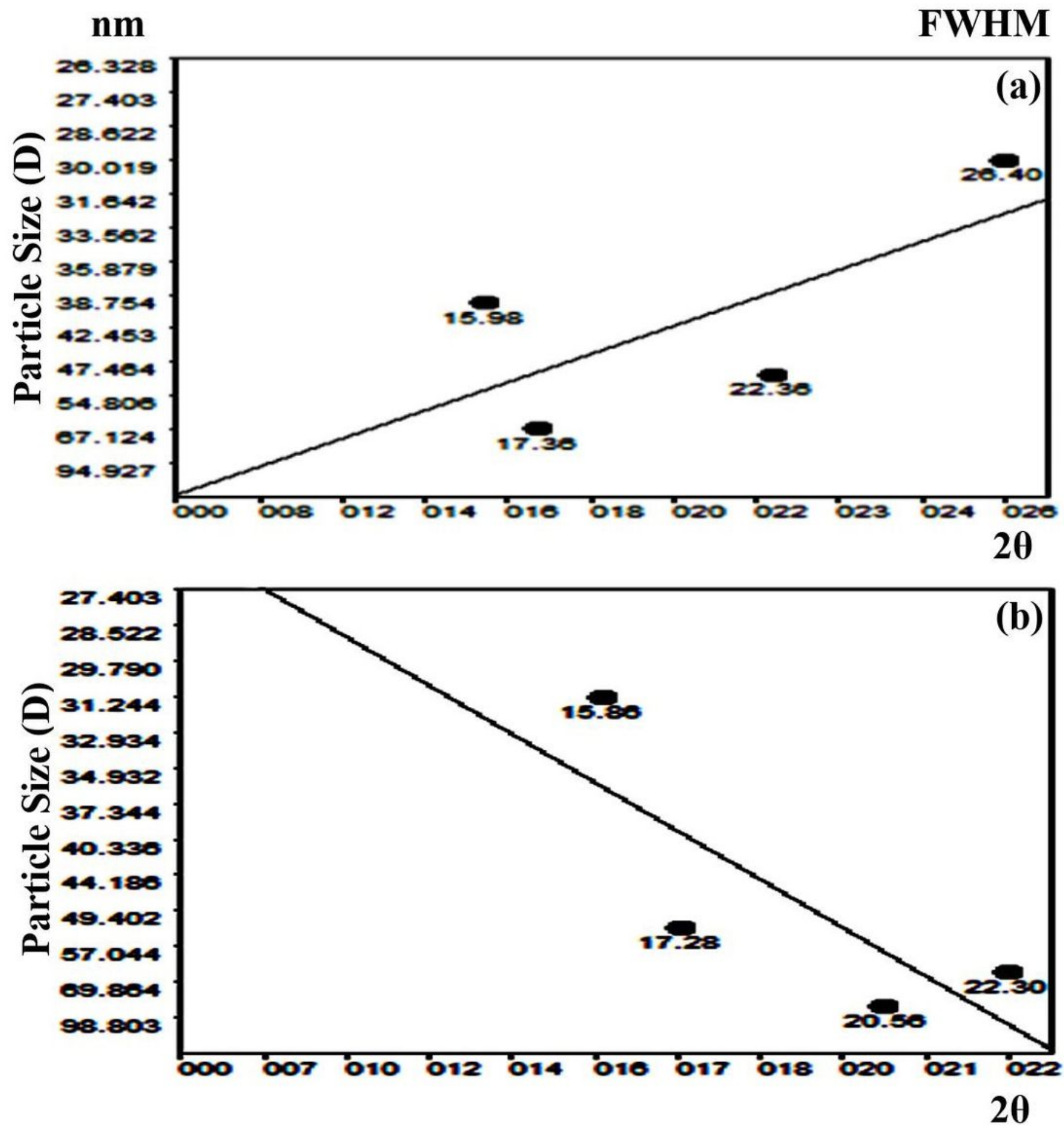

Figure 4

Particle size for; (a) calcinated bentonite clay and (b) ball milled calcinated bentonite using W-H size analysis. 


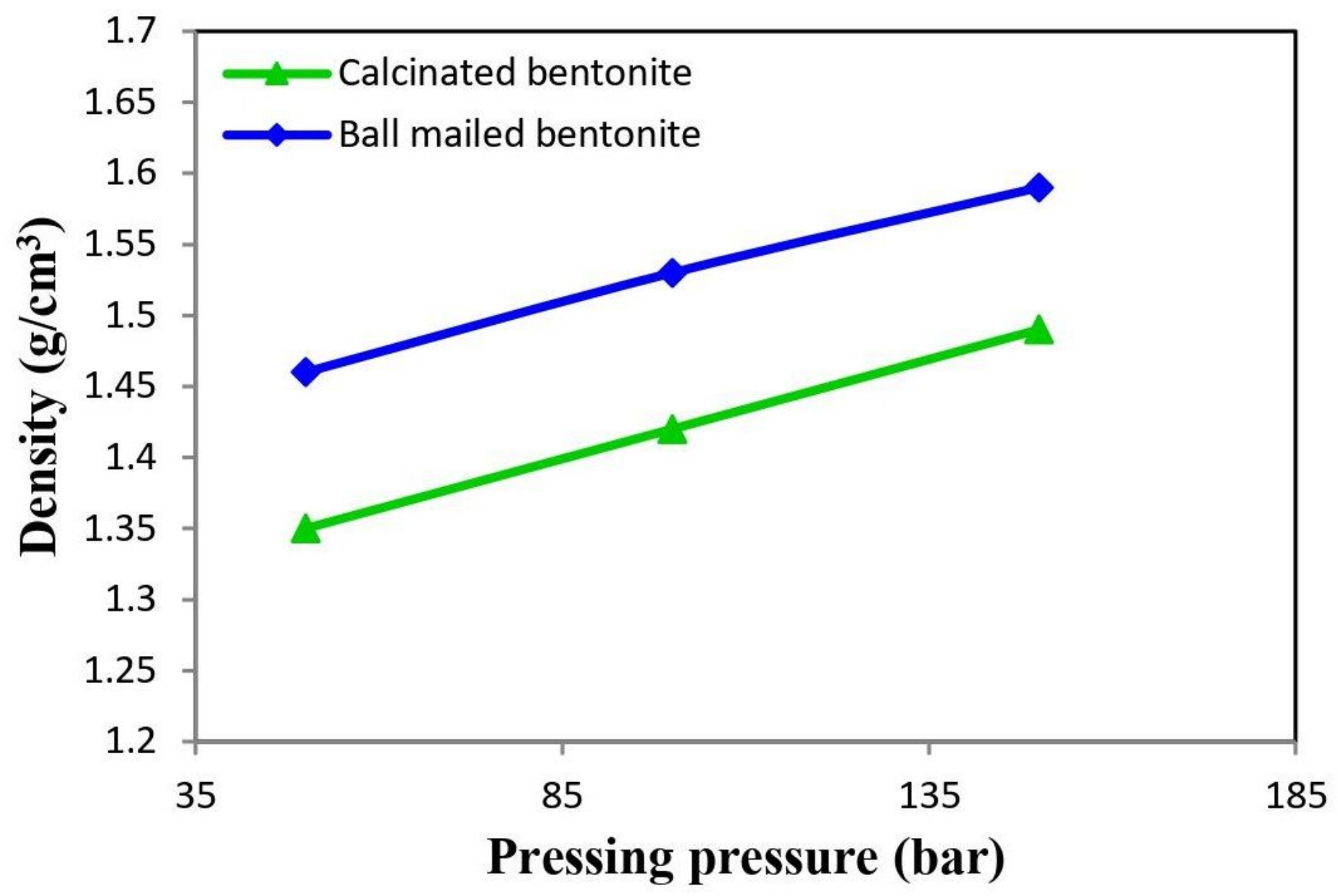

Figure 5

Density measurements of calcinated and ball milled bentonite clay at different pressing pressure. 

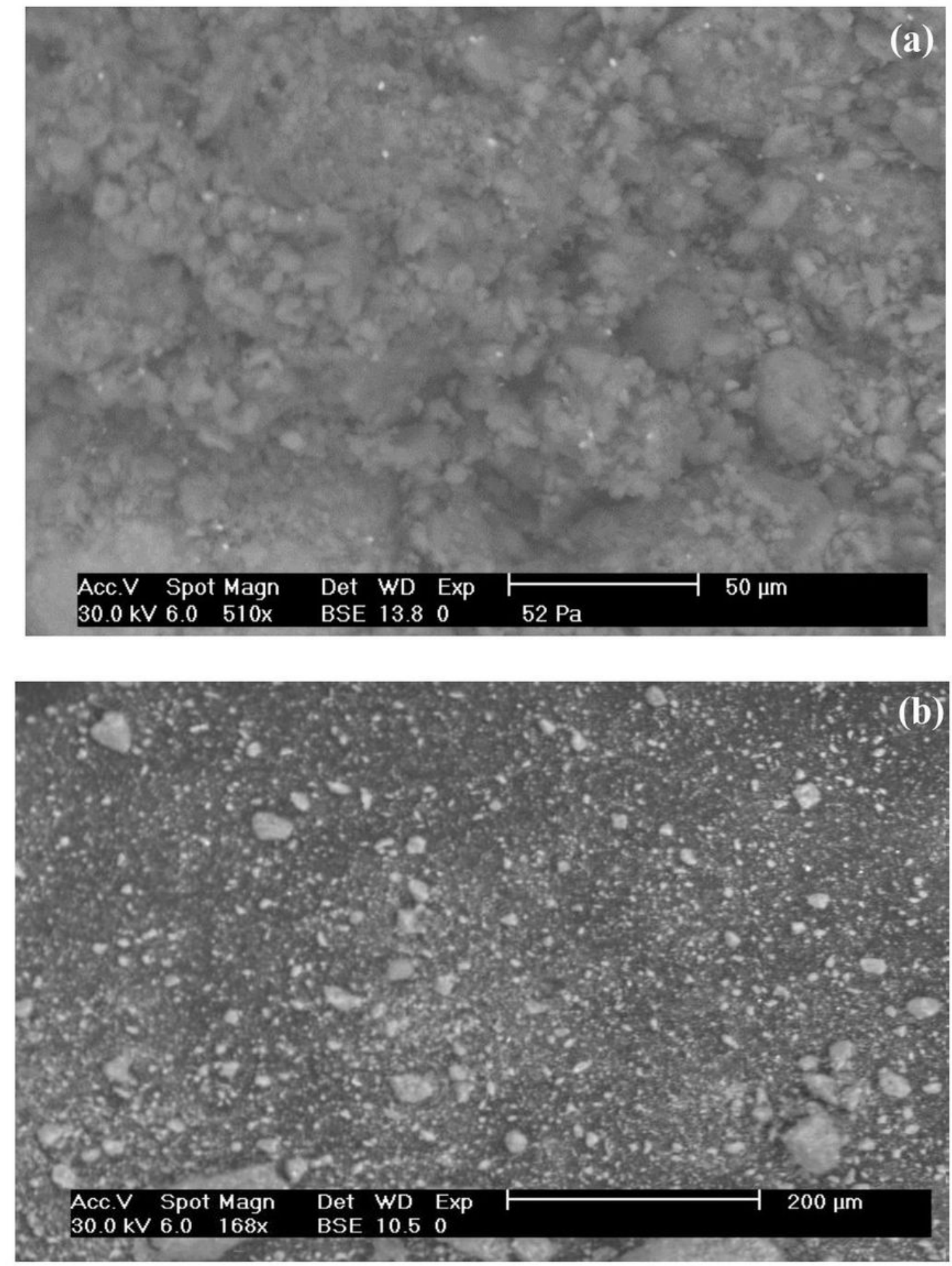

Figure 6

SEM micrograph for; (a) calcinated bentonite clay and (b) ball milled bentonite clay. 


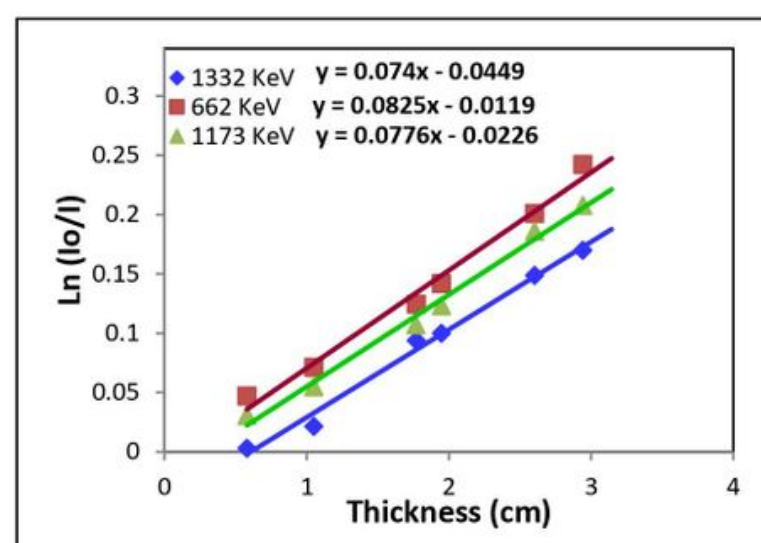

(a)

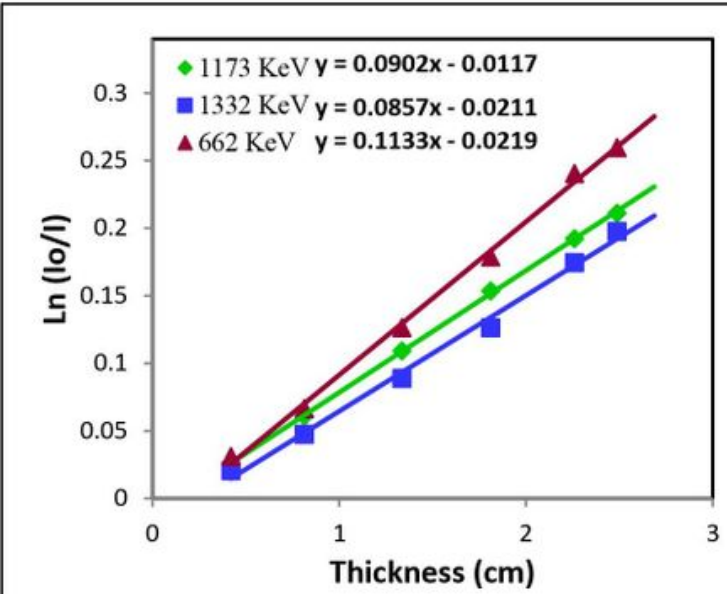

(c)

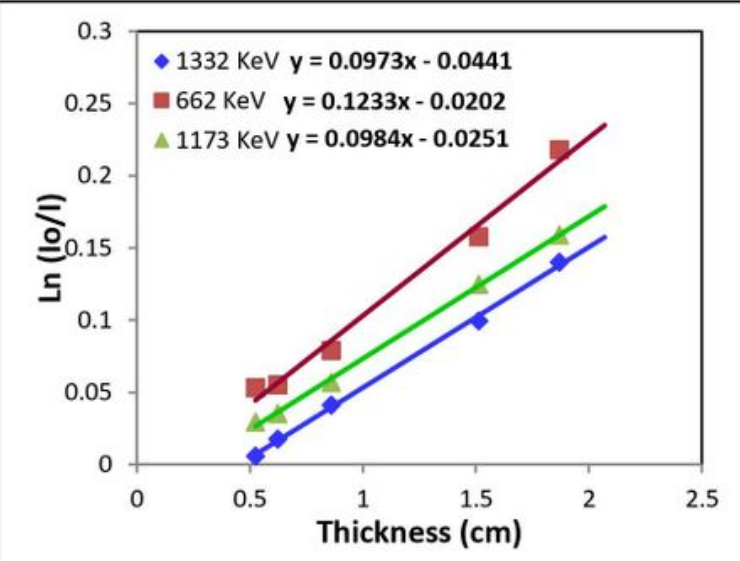

(e)

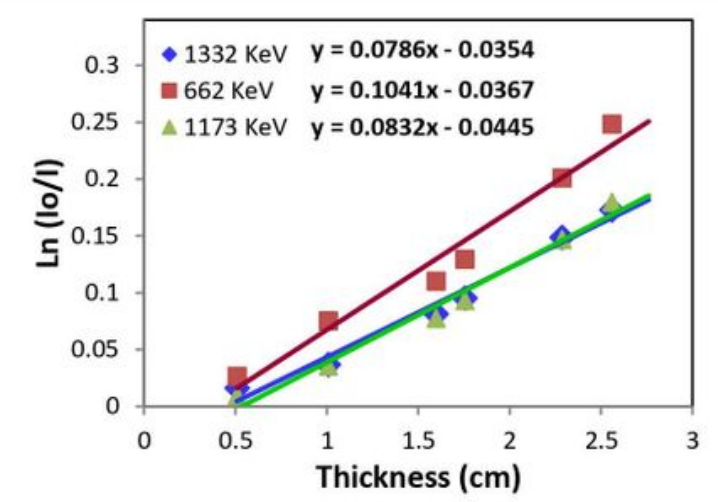

(b)

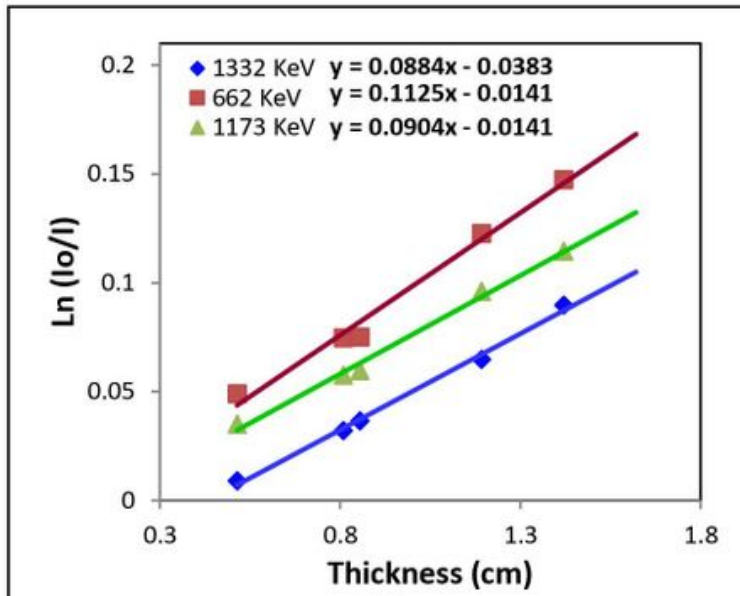

(d)

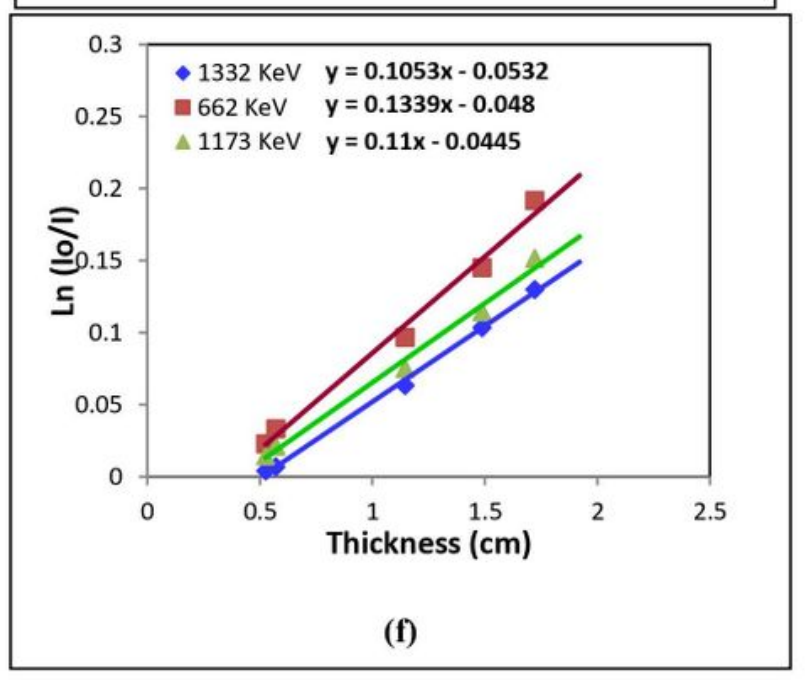

\section{Figure 7}

Gamma transmission through (a) calcinated bentonite pressed at 50 bar (b) 100 bar, (c) 150 bar, (d) ball milled calcinated bentonite pressed at 50 bar, (e) presed at 100 bar and (f) pressed at 150 bar at different thicknesses and different energies. 

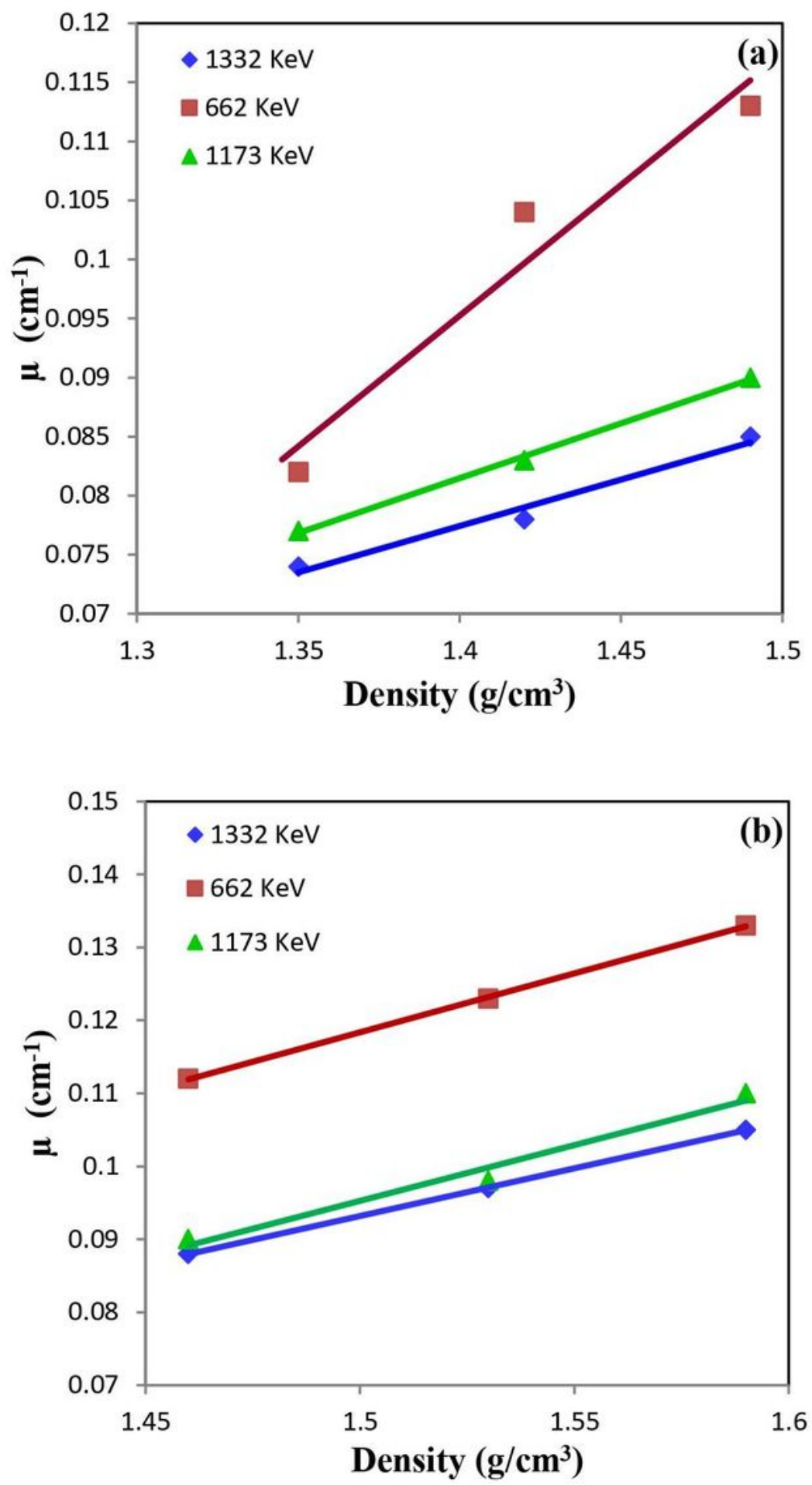

Figure 8

Linear attenuation coefficient versus density for; (a) calcinated bentonite at different energies and (b) ball milled calcinated bentonite at different energies. 


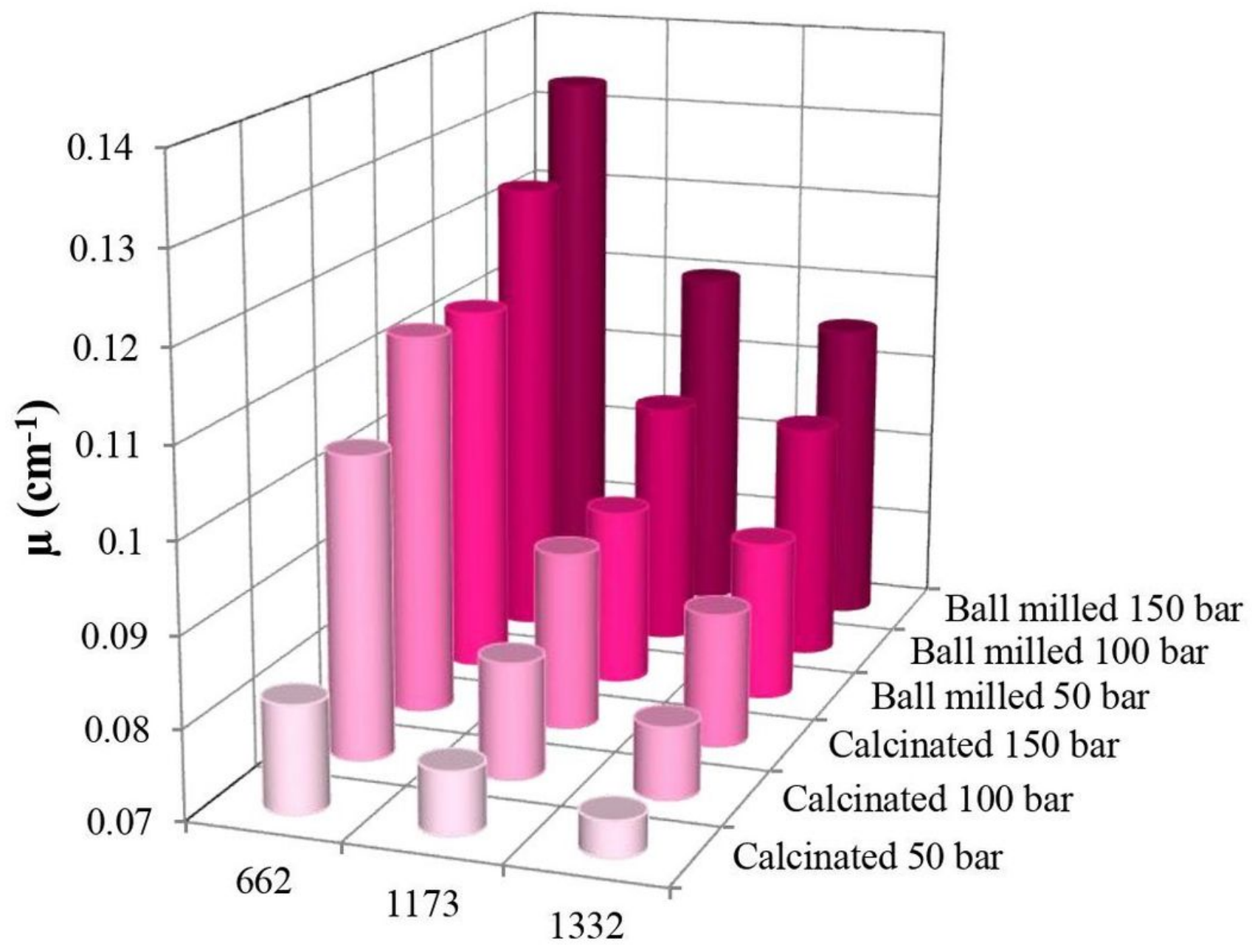

Energy (keV)

Figure 9

Linear attenuation coefficient versus energy for calcinated and ball milled bentonite at different pressing pressure. 


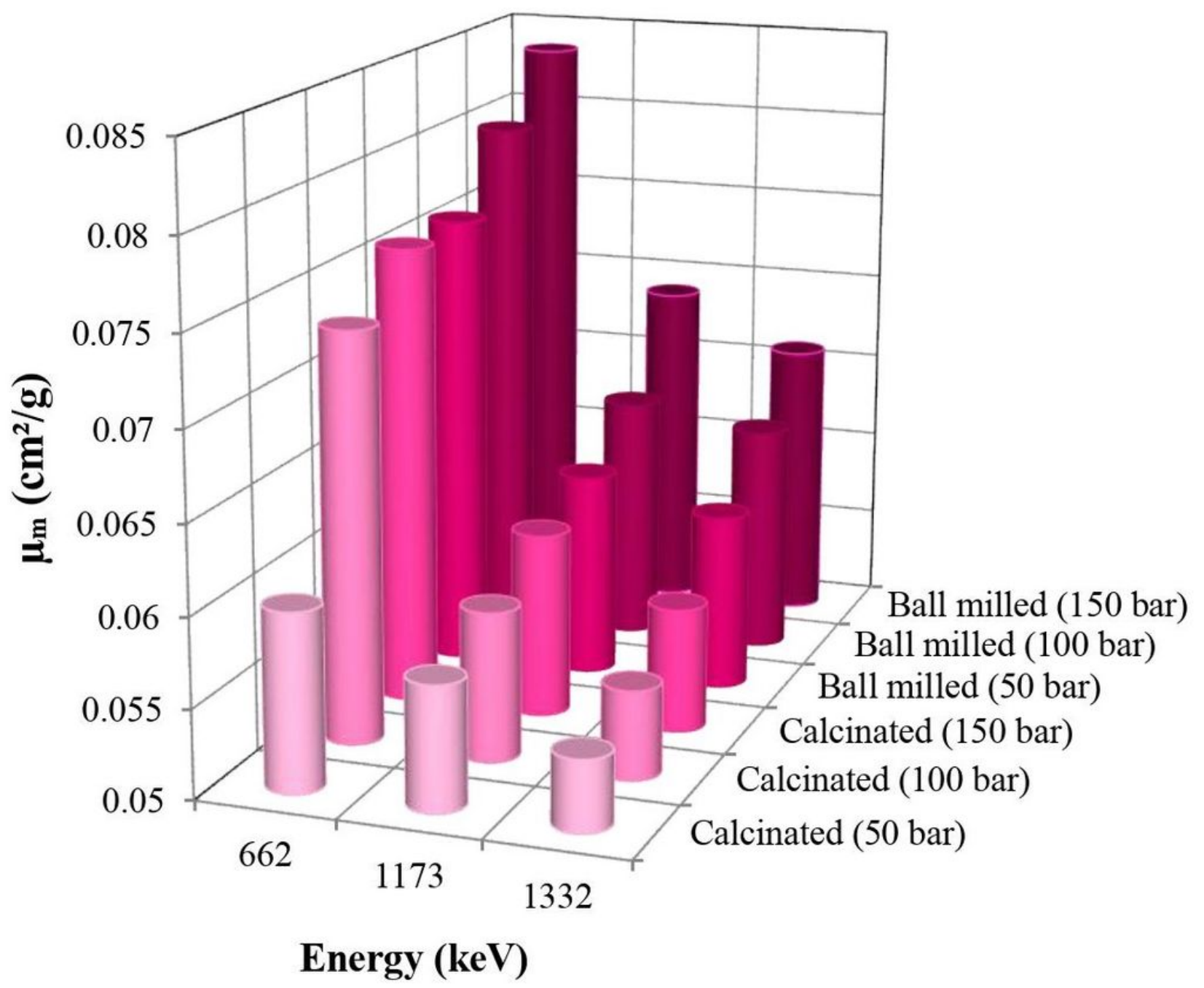

Figure 10

Mass attenuation coefficient versus energy for calcinated and ball milled bentonite clay at different pressing pressure. 


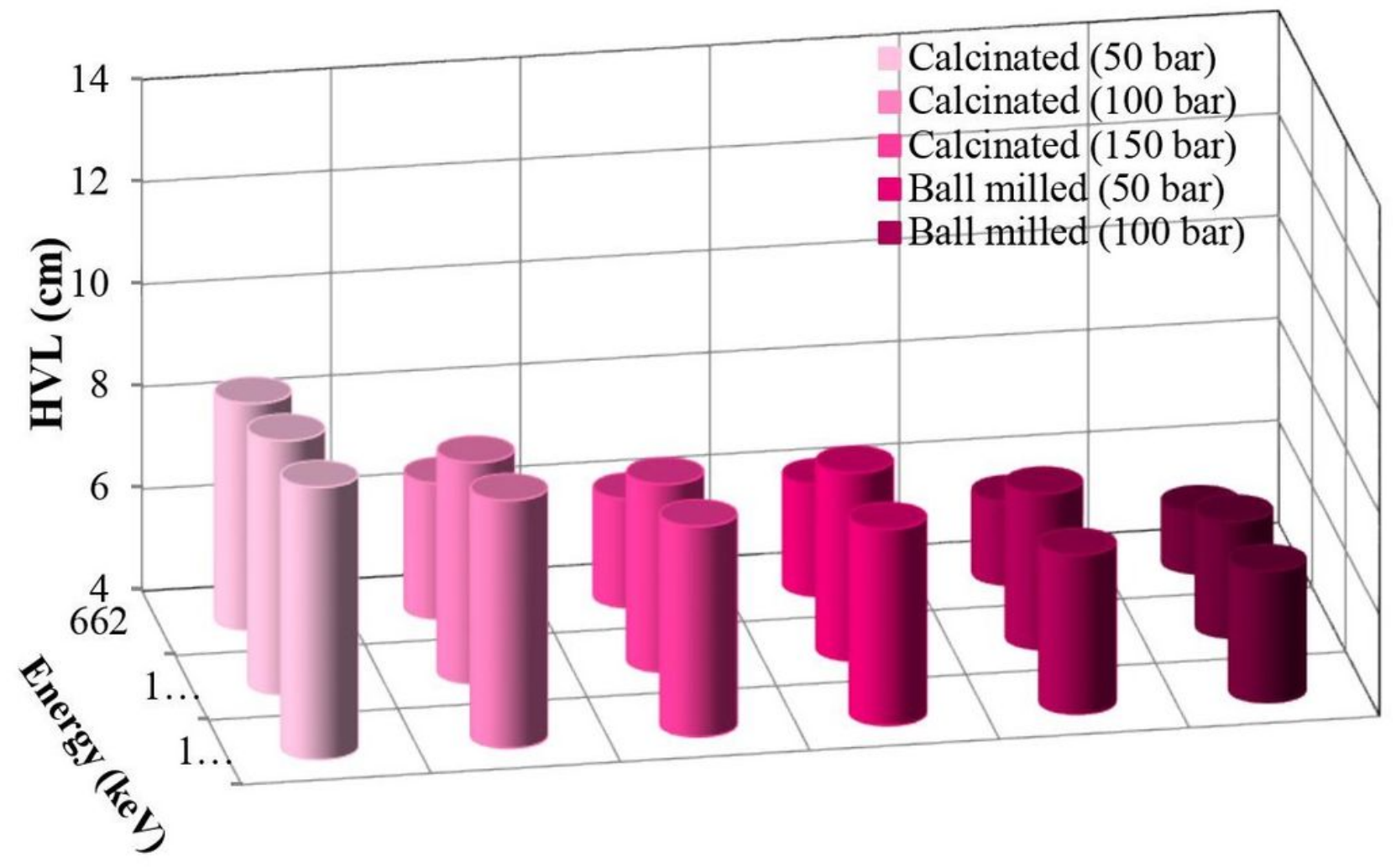

Figure 11

Variation of HVL with energy for calcinated and ball milled bentonite clay at different pressing pressure. 


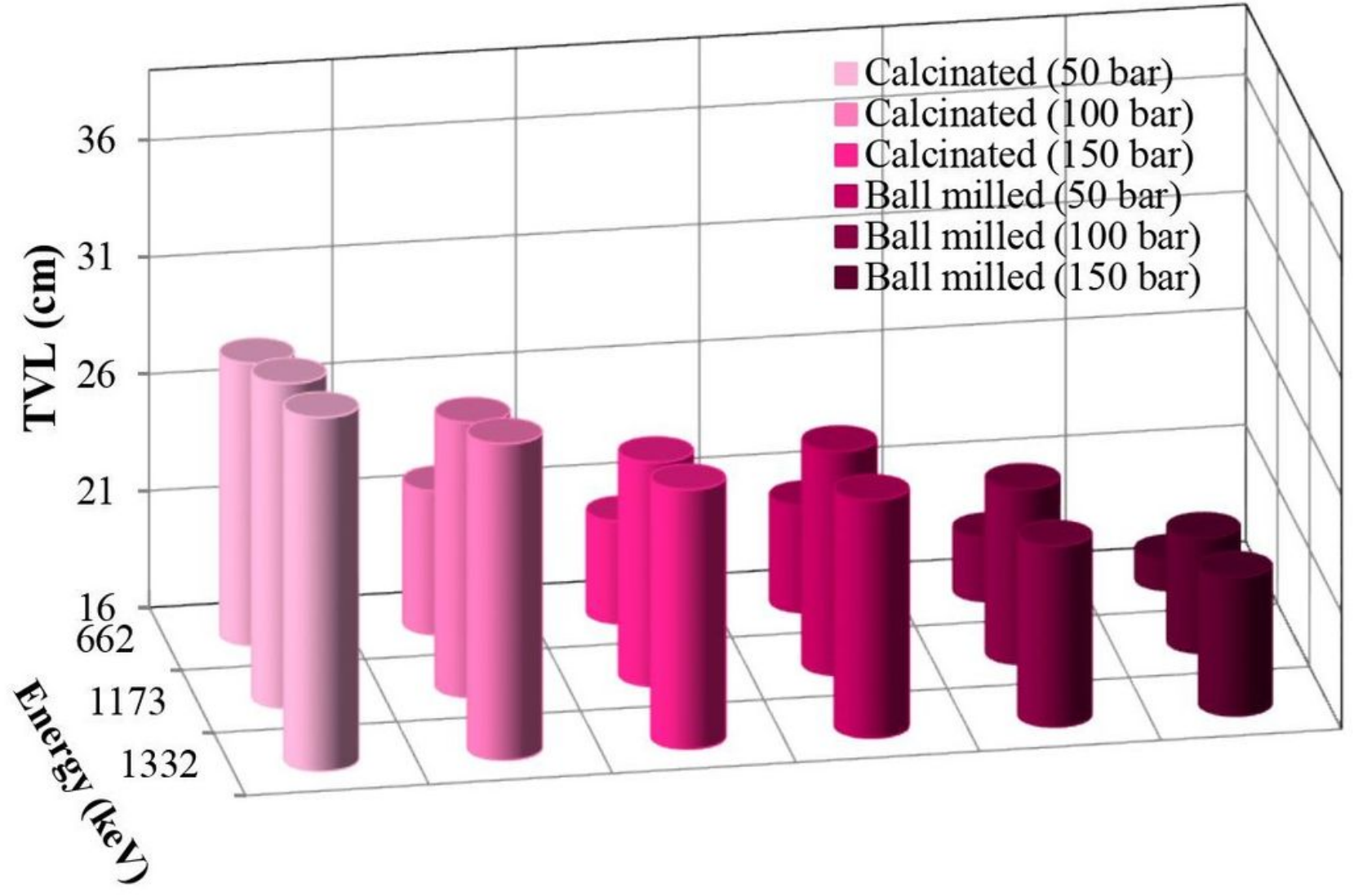

Figure 12

Variation of TVL with energy for calcinated and ball milled bentonite clay at different pressing pressure. 


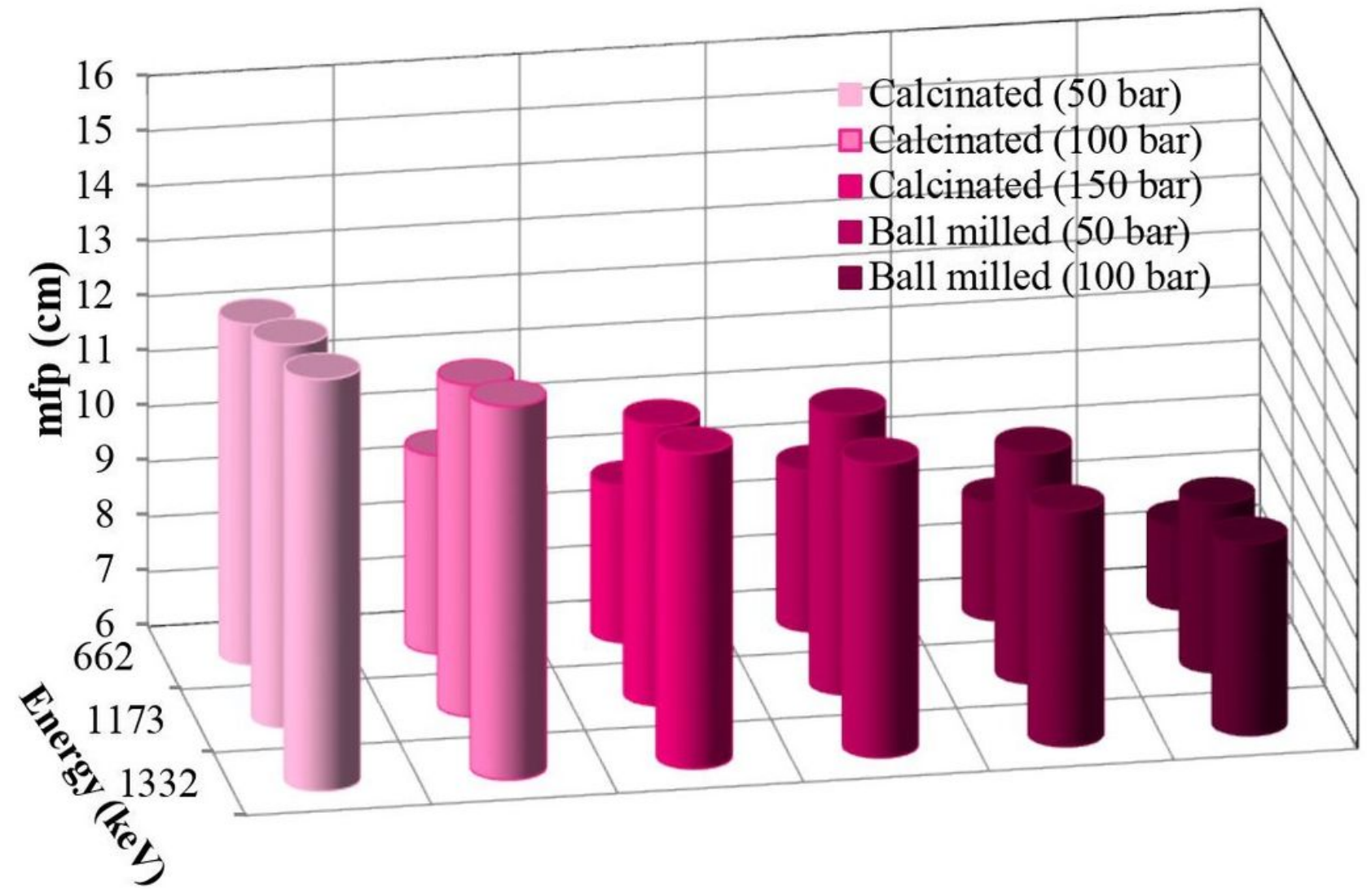

Figure 13

Mean free path versus photon energy for calcinated and ball milled bentonite clay at different pressing pressure. 